\title{
Audit Expectation Gap Debates: To What Extent Audit Expectation Gap Defence Auditors?
}

\author{
Adelia Yulma Budiarto \\ Accounting Department, Faculty of Economics and Communication \\ Bina Nusantara University \\ Jakarta 11480, Indonesia \\ adelia.yulma@binus.ac.id \\ *Correspondence: adelia.yulma@binus.ac.id
}

\begin{abstract}
The research aimed to unpack the debate of the audit expectation gap that occurs between the audit profession and the general public. This qualitative research intended to revisit what shapes audit objectives and their difficulties by drawing upon prominent academic debates and publicly available reports. This research argues that the concept of the audit expectation gap is two-fold. At first, the gap has been seen as destruction for the audit profession. However, to a certain extent, the gap is useful for auditors'defence mechanisms from critics, though auditors have to be alert that the gap might turn into an offensive medium and fuel the criticism. To illustrate this contention, this research argues the following. Firstly, the series of accounting scandals, changes of auditing standards towards fraud, and the phenomenon of audit explosion are giving more autonomy for auditors to protect the professions' best interest. Secondly, the issue of audit independence and conflict of interest is favourable for auditors to sustain the gap and maintain the monopoly of the audit business. Instead of being left behind, auditors earned public legitimacy because they manage to build a distinctive image as an expert who was able to work for the greater public interest in a complex, uncertain, conflicted, and stressful working environment. Thirdly, public demand for transparency is hurting audit professions because it increases public mistrust and might reveal audit confidentiality. It even fuels criticism further because auditors have communication difficulties.
\end{abstract}

Keywords: Audit expectation gap; Auditor; Fraud.

\section{INTRODUCTION}

Society relies extensively on advice from experts. In the context of financial information, market is leaning on the arm of auditor to be the watchdog of organisations' reporting process. This research aims to explore the audit profession because external auditors have been known as a trust engendering technology (Power, 1999) where society expects audit procedures to be able to verify the reliability of financial report.

'This 'public watchdog'function demands that accountant maintain total independence from the client at all times and requires complete fidelity to the public trust."

Argued by a former Chief Justice of the United States Supreme Court as he demonstrates that auditors' role is important for the operation efficiency of public trust in capital markets (Bazerman \& Moore, 2011). In a more extreme contention, Sikka (2009) states that external auditors' opinion is useful to impress the public that corporations are accountable and clean from corruption. However, the role of auditor is being contested over the wave of major corporate accounting scandals, starting with their involvement in McKesson and Robbins case in 1939 until the massive incident of Enron 2001. The series of iconic scandals leave public a doubt in audit profession, as Coffee (2006) asks in his book: why did the watchdogs not bark? 
Auditors' performance is at the centre of public attention. Society is questioning auditors' capabilities because they are expected to be a gatekeeper, yet they get involved in many corporate scandals. It leads to criticism towards the profession where society contested the meaning of audit results, reliability of auditors' independence and efficiency of audit procedures. This situation introduces the concept of 'audit expectation gap' which defined as a gap lies between the expectations' society had about auditors and the actual auditors' performance perceived by society (Porter, 1993). In responding to the pervasive critiques from investors, politicians, regulators and media, audit practitioners have mostly claimed that the underlying issue is a public misunderstanding (Power, 1999). Society portrays auditors as a watchdog responsible for detecting red flags of fraud. Meanwhile, auditors argued that due to cost and technical feasibility, management and its control systems are the ones primarily responsible for fraud detection and prevention. In this regard, audit practitioners demonstrate the urgency to reduce and close the gap. Thus, this research designed to explore auditors' approach to deal with society's critiques to the extent of the gap debates.

The phenomenon of audit expectation gap is not a new memoir, as Humphrey, Moizer, \& Turley (1992) elaborate the concern over auditors' role and responsibilities have existed for more than a century. The history began in the late period of the nineteenth century when non-auditors acknowledged high amounts of audit wrongdoings involved in corporate scandals. It starts with the case of City of Glasgow Bank in 1878 where auditors misrepresent balance sheet accounts then followed by the dramatic failings of McKesson and Robbins in 1939 which is known as infamous scandal long before Enron destruction (Humphrey et al., 1992). There are many critiques addressed to auditors for their failure on detecting an error, collecting evidence, inadequate reporting and forming an inaccurate judgement on companies' accounting treatment in financial reports (Russel, 1991). As a result, US Securities and Exchange Commission (SEC) committee investigation concluded that the existing audit standards were inadequate to serve its purpose and auditor has less obligation for fraud detection due to socioeconomic changes (Humphrey et al., 1992; Porter, 2007).

Later in the early twenty-first century, auditors were still entangled in corporate scandals, including two major incidents of Enron and WorldCom. Enron was a fast-growing energy company with $\$ 100.8$ billion revenue in 2000. It ranked as number seven of Fortune 500 list but then filed for bankruptcy shortly after announcing significant issues with related party transactions in October 2001 (Seligman, 2002). Likewise, WorldCom filed for bankruptcy due to the discovery of accounting fraud that overstates pre-tax income when the leading telecommunications company had revenue of $\$ 30$ billion in 2002 (Kaplan \& Kiron, 2007). The scandals resulted in two largest bankruptcies in US history and exposed the complete breakdown in corporate governance, both the failures in internal control and external monitoring (Coffee, 2006). The scandals were hidden from public because their external auditor, Arthur Andersen, is not performing the role of gatekeepers as Andersen alleged to be involved in the fraudulent accounting. Henceforth, the review of accounting scandals history shows that the gap appears to be a recurring problem since the old time. Auditors' existence is being questioned because auditors failed to act as independent intermediaries and unable to communicate any red flags of accounting frauds when society trusts and expects them to do it.

Auditors have an on-and-off relationship with fraud detection's responsibility. Dating back to the early sixteenth century, auditors have a fundamental role in detecting fraud. Montgomery (first auditing text in 1921) addressed the audit's main goal is to detect and prevent fraud and error (Albrecht et al., 2009). However, the massive fraud of McKesson and Robbins case in 1939 shocked the accounting professions. It influences the rearrangements of audit objectives, where Brown (1962) explains a consensus declared that 'auditor could not, and should not, be primarily concerned with the detection of fraud'. Statement of Auditing Procedures (SAP) 1 by American Institute of Certified Public Accountants (AICPA) expressed that auditors 'is not designed to discover all defalcations, because that is not its primary objective' (AICPA, 1939). The standard is positioning auditors aside from fraud detection and stating that auditors' main objective is to determine the fairness of financial reports (Brown, 1962). SAP 30 released in 1960 to clarify that even auditors have to be sceptical of any fraud possibility may occur during audit process, the primary responsibility of fraud detection lies on management.

In 1974, AICPA set “Commission on Auditor's Responsibilities" to re-examine auditors' responsibility in fraud detection because many critiques were addressed to auditors after the Equity Funding scandal. General public is blaming auditors because there are many irregularities discovered after audited financial statements released (Farrell \& Franco, 1998). The phrase of 'expectation gap' makes its first appearance in the Cohen Commission's report in 1978 (Humphrey, 2007), where the report advocates 'possibility of a gap exists between the performance of auditors and the expectations of financial statements' users' (AICPA, 1978). The expectation gap issues were continuously spreading to all over the world. It influenced the establishment of similar board in 
the UK and Canada to investigate and develop recommendations on audit and fraud. In the following years, the Public Oversight Board (POB) of AICPA noticed that audit practitioners are unwilling to accept greater duty to detect fraud after the publication of Statements on Auditing Standards (SAS) 16. The issuance of SAS 53 and SAS 54 also had little impact on reducing liability lawsuits against auditors because professional scepticism hasn't been properly applied to discover fraud (Chui \& Pike, 2013). The establishment of similar panels in different countries aimed to reconsider auditor functioning to lower the gap. However, the contradictive reaction from auditors for fraud detection responsibilities extended the gap even more.In 1997, audit standards finally committed to auditors' fraud detection responsibility and used the phrase 'fraud' in the title of auditing standards for the first time. SAS 82 demonstrates that auditor is responsible for conducting fraud risk assessment and its modification to the audit plan. Auditors have to assess the likelihood of risk factors during an audit, nevertheless auditors' obligation to detect fraud falls under the key concepts of materiality and reasonable assurance (Mancino, 1997). Later after the Enron case in 2002, SAS 99 supersedes SAS 82 in exchange to provide better guidance of fraud detection, the standard engages in meaningful risk assessment procedures and increases audit effectiveness (Marczewski \& Akers, 2005). The long road progress discussed above demonstrates the significant changes in auditors' responsibility towards fraud detection. The criticism and scandals lead to the reformation of audit priorities. Auditors' role is shifting to reduce audit expectation gap that becomes a recurring issue for audit practitioners all around the world. The reactions to various accounting scandals, transformation of audit environment and changes of standards and regulations gradually shape auditors' role and responsibility.

This research argues that audit expectation gap is a two-fold concept. At first, the gap has been seen as destruction for the audit profession. However, to a certain extent, the gap is useful for auditors' defence mechanisms from critics, though auditors have to be alert that the gap might turn into an offensive medium and fuels the criticism. To illustrate this contention, this research argues the following. Firstly, the series of accounting scandals, changes of auditing standards towards fraud and the phenomenon of audit explosion are giving more autonomy for auditors to protect the professions' best interest. Secondly, the issue of audit independence and conflict of interest is favourable for auditors to sustain the gap and maintain the monopoly of audit business. Instead of being left behind, auditors earned public legitimacy because they manage to build a distinctive image as an expert who able to work for the greater public interest in a complex, uncertain, conflicted and stressful working environment. Thirdly, public demand for transparency is hurting audit professions because it increases public mistrust and might reveal audit confidentiality. It even fuels criticism further because auditors have a communication difficulty.

This research is structured to develop the argument in three sections. First, it unpacks the concept of audit expectation gap by exploring the effects of accounting scandals, analysing the shifting of auditors' responsibility towards fraud and investigating auditors' perspective of the gap by taking account of audit explosion theory. Second, this research analyses the contributing factors that sustain the gap, it covers the influence of independence issues, conflict of interest and auditors' competence to work in a complex and demanding environment. Lastly, this research discusses the factors that fuel the gap debates, including the demand for transparency, potential mistrust and communication difficulty. As such, this research constructed to scrutinise to what extent an audit expectation gap is useful and convenient for auditors to defend their position, or in either way it might be useless and even fuel the criticism.

\section{METHODS}

The objective of this research is to explore arguments from prior researchers about the debate of audit expectation gap. The research was conducted using qualitative method by review and scrutinise researchers' critics either from theoretical, empirical basis, or literature review. With the aim to unpack the debacle of audit expectation gap for auditors, investors, organisations, regulators, media and general public, this research intended to revisit what shapes audit objectives and its difficulties by drawing upon prominent academic debates and publicly available reports.

This qualitative research is taking systematic organisation into account in presenting the debate. Literature drawn in this research was collected from several audit research. The fundamental discussion conducted in the research was based on the theory of audit expectation gap and audit explosion. Then, the discussion was expanded with two main research questions, which the first one is questioning of what factor sustains and feeds the audit expectation gap. Independence issue, conflict of interest, and competence contestation are considered to be the three aspects that sustain the audit expectation gap. Secondly, the research asked of what factor fuels the auditor criticism. The analysis widens up to examine the demand of transparency along with the mistrust and 
communication difficulty occurs in between auditor and general public. Accordingly, figure below presented the order of this research discussion topics.

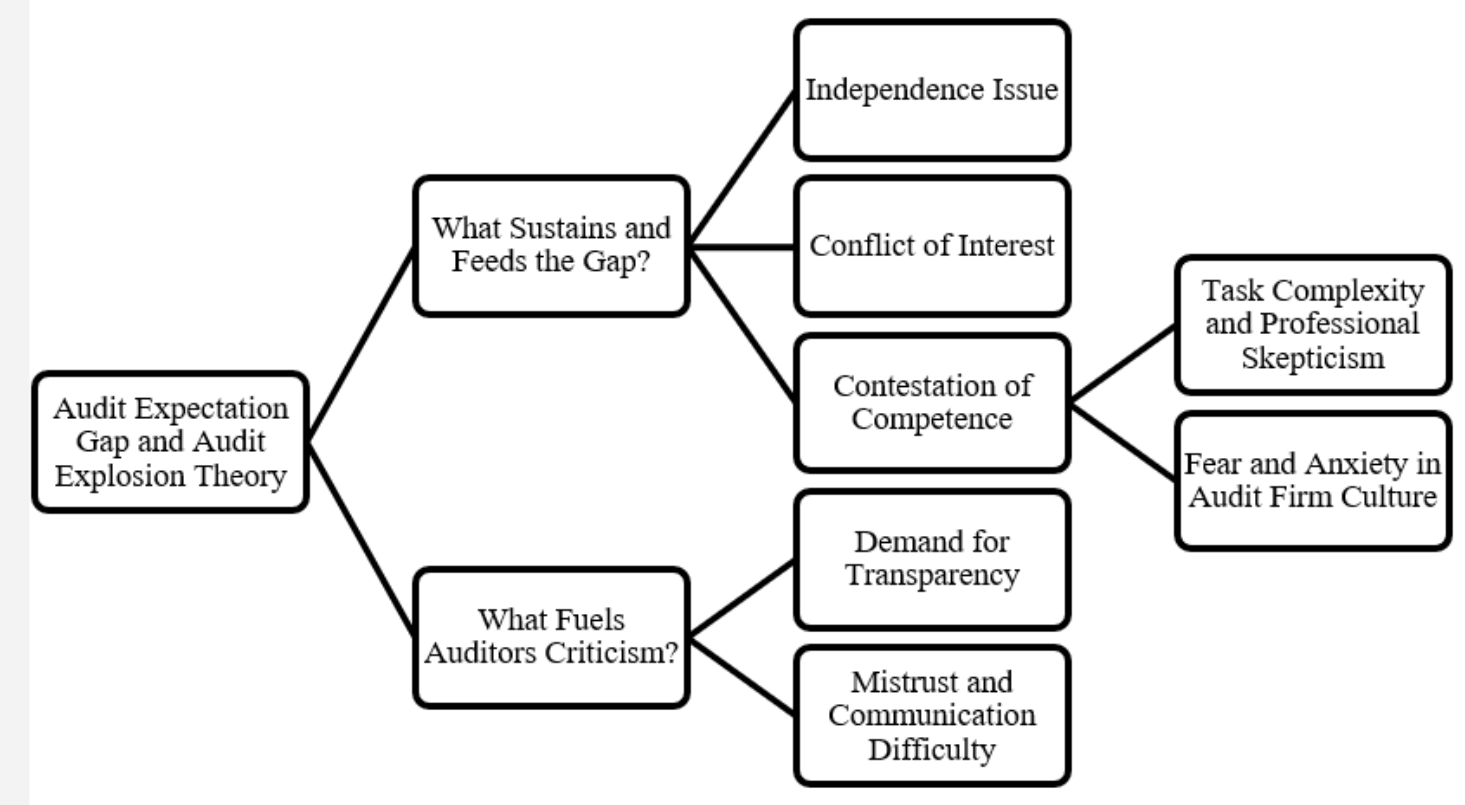

Figure 1: Research Discussion Topics Mapping

\section{RESULT AND DISCUSSION}

\section{Audit Expectation Gap and Audit Explosion Theory}

The long-standing problem of audit expectations gap appears to be less convenient for auditors. The historical pattern of shifting auditor responsibilities on fraud detection shows that audit practitioners tried to reduce the gap. Porter (1993) argues that urgent and effective actions are needed to close the gap so it could prevent irreparable damage of the audit profession's image. In contrast to that argument, the gap is somehow portraying an advantage of autonomous position for auditors. Humphrey et al. (1992) argue that.

Auditors are not responding diligently to the changing of public demands due to society misconceptions; they rather being seen in a more proactive and economically interesting light with respect to maintaining the presentation of independent and highly competent individuals to defend its professions' interests.

Interestingly, the gap is somehow beneficial for auditors. The distance of auditing knowledge between auditors and general public formed auditor to be the only profession able and competent to conduct organisations' financial statements verification, regardless of the criticism arises. It is supported by the fact that the gap is advantageous for securing auditor economic success since the job is uneasy to replicate, as Power (1999) argued as 'a certain obscurity in the professional craft gives the practice its aura and sustains its monopoly privilege'. Thus, far from being disadvantageous, the gap is helpful to be auditors' shield to defend and strengthen their position as market actors.

The theory of audit explosion introduced by Power (1994) shows the growth of audit associated with the reform of public management processes due to the increase of regulations and expanded institutional significance of audit. There is an increasing number of assurance and monitoring practices in non-financial fields of study such as environmental audits, forensic audits and data audits. Humphrey \& Moizer (1990) illustrate audit as a socially-constituted activity that the nature of audit can serve diverse roles and functions. The notion of audit has been institutionalised as an idea of independent and neutral verification that could be an instrument to uphold transparency of various performance. Despite the criticism received by auditors, society demands the existence of assurance for greater accountability.

Power (2005) elaborates the positive impact of the audit explosion such as improvement in financial management, development of organisations' self-monitoring capacity, organisational learning opportunities and increase of public responsiveness. However, the idea of audit explosion might establish a readily auditable system which leads to a decrease of organisational trust and distract professional attention (Power, 2005). The range of 
intended and unintended consequences of audit explosion challenge the auditors to be operationally sceptical and independent in order to be credible and trusted. Auditors' commitments to maintain scepticism and independence managed to increase their competence and put society at a greater distance. This situation is favourable to ensure the sustainability of auditing business because without the gap audit process would be fully transparent and easily replicated by non-auditors. Therefore, the gap managed to be a useful shield to maintain auditors' position. Even though audit deals with accounting scandals, audit environment transformed and audit standards keep changing, evidence shows that auditors have their autonomy to regulate, defend and advance the professions' best interest.

\title{
What Sustains and Feeds the Gap?
}

The concern of audit expectation gap is at the heart of audit practitioner's debacle because it is directly associated with auditors' well-being. A bigger gap may reduce auditors' credibility and bring a potential loss of revenue. Sikka et al., (1998) argue that the gap is hard to be eliminated due to social conflict where auditors are not in a sovereign position to clarify and defend themselves to the public. In contrast, this research argues that auditors have a willingness to maintain the existence of the gap to protect the professions' speciality and sustainability. The second part of this research explores the factors that contribute to sustain and feed the presence of the gap.

\section{Independence Issue}

Auditors are expected to act as a gatekeeper in an organisation, however numerous auditors' involvement in fraudulent accounting put auditors' independence issue in a spotlight. Coffee (2006) described gatekeepers as independent professionals who monitor and screen out flaws in organisations then communicate the signal to investors. Corporate clients engaged and paid auditors in a private contracting, in returns auditors must maintain their independence as a reputational intermediary to the public, investors and other parties who rely on the verified information. However, many cases of external auditors' involvement in fraudulent scandals made society questioning auditors' role as independent gatekeeper. For example, Arthur Andersen was admitted as one of the Big 5 public accounting firms, had about 2,300 audit clients and known as one of the most respected professional services. Despite its great credibility, Andersen failed to maintain their independence and associated with notorious accounting scandals of Waste Management, Sunbeam, WorldCom and Enron (Coffee, 2002).

\begin{abstract}
"The system begins with the corporate managers and directors, whose actions are to be audited, going out and choosing the auditor. They hire the independent audit firm, determine the fees to be paid and have the power to fire the auditor for any reason. The independent audit firm often provides tax and management consulting services to the same corporation it audits. Can we really expect an audit firm to remain independent when its audit fees, and perhaps substantial consulting fees, are directly related to pleasing the corporate managers being audited?"
\end{abstract}

Cited from Humphrey \& Moizer (1990) when John Dingell, former United States Representative, stressing the complicated relationship between auditors and management. Society doubt the value of audit independence because it is hard to separate the business from the profession, it is problematic whether auditors serve the clients or broader public interests since management is the one who hires and fires auditor. In response to this condition, Coffee (2002) introduced a 'general deterrence' theory which analyses the cost and benefits of auditors compromising their independence attitude. Coffee argues that deterrence of audit failure is declining because, first, acquiescence in misconduct becomes rational when there are agency cost problems from non-audit services fees and incentives for cross-selling consulting services. Second, the financial gain of pleasing the clients increased while the potential cost for litigation decreases. Following Kershaw (2006), auditors might have incentives to adjust their independence level when the financial benefit to acquiesce managements' demand outweighed the costs of compromising independence. Auditors have to pay some costs for acting non-independently, such as litigation exposure, reputational damage and disciplinary sanctions from professional bodies (Kershaw, 2006). But when the cost imposed is smaller than the expected revenue, auditors have strong economic incentives for their personal interest and welfare, which Bazerman \& Moore (2011) express as auditors' mechanism to adapt in self-serving ways. Therefore, one has to be careful because independence issues could break any time when auditors find the benefits to act non-independently is greater than the cost imposed. The independence issue sustains audit expectation gap because auditors' willingness to compromise their independence puts a greater distance for public to trust auditors.

\section{Conflict of Interest}

It is interesting to take a closer analysis on the conflicting relationship between auditors and management, as Moore et al., (2006) argue that conflicts of interest lie at the root of mismanagement and audit failures. When 
external auditors appointed by companies to perform audit procedures, auditors should behave honestly and independently, even if their whole or part of future audit revenue and business sustainability are at stake if they failed to satisfy the clients. Moizer (2007) believes that audit is a concept about human nature, who will express the truth unless they have incentives to be dishonest. Auditors are trusted to be more independent than managers who tend to manipulate financial reports for better performance compensation. However, since directors and management are the ones who appoint and determine audit fee, auditors may be reluctant to jeopardise their career. As a rational economic individual, auditors may act in such a way that maximises their own utility.

Furthermore, this situation is getting worse when auditors engage with clients in a long-term period and build a common identity between them. As prior studies found that the longer auditor-client relationships last, the worse auditor independence and audit quality can be produced (Moore et al., 2006). Both cases of Enron and WorldCom shows that management has the primary goal to maximise the Company's stock price. Enron hides their financial instability through special purpose entities (SPEs), and WorldCom conducts series of accrual reclassification and expense capitalisation, which both frauds occurred primarily stemmed from the tone-at-the-top corporate culture. In this situation, external auditors have a conflict of interests, whether to serve the public or serve companies because they are not economically independent from their clients. For example, Arthur Andersen earned a legit amount of revenue from Enron in 2000 whereabout \$25 million for audit and \$27 million for consulting services (Coffee, 2006). Despite the poor accounting treatment, weak internal control and conflicting fees from audit and non-audit services, Andersen signed off the corporate reports because the auditor-client relationship has lasted long and become too valuable to lose. Moore et al. (2006) support this argument saying that auditor independence may be compromised when client firms help auditors to develop job and career opportunities, auditing has become more about providing advisory roles to client entities rather than serving credibility assessment (Humphrey \& Moizer, 1990). Thus, the institutionalisation of auditor-client relationship is indeed conflicted and contributes to a larger gap between societal expectations and assurance performance because a conflict of interest affects auditors' judgement in doing audit practice.

\section{Contestation of Competence}

Around the time of financial crisis in 2008, Ireland former minister described auditors as an overrated profession saying that,

"Auditor is a joke and a waste of time. They are lick-arses for the management of companies, because corporate governance doesn't work in our society [...] Auditors are not independent but they are bloodywell paid." (O’Halloran, 2008).

There are many critiques addressed to auditors that doubt their competence and fuss over the overpaid audit fee, auditors successfully maintain their existence for hundreds of years. The theory of audit explosion represents how society has been institutionalised with the idea of audit as an essential tool to provide assurance of performance quality. Despite the criticism, society believed auditors are competent and helpful to give useful information to its users for better decision making. This section elaborates how audit procedures complexity, debate on professional scepticism, fear and anxiety of audit culture managed to construct auditor as a credible reputational intermediary.

\section{Task Complexity and Professional Skepticism}

In a principal-agent theory where investors act as principal and management as an agent, auditors become a risk management mechanism for principals to reduce information asymmetry and reassure the financial information are reliable. Auditors are responsible for making an objective assessment on accounting methods, treatments and estimates made by companies before disclosing it (AICPA, 1978). In delivering audit procedures, auditor deals with complex and uncertain accounting estimates of financial information, for example fair value accounting (FVA). According to Statement of Financial Accounting Standards (SFAS) 157, the FVA measurement used "the price that would be received to sell an asset or paid to transfer a liability in an orderly transaction between market participants at the measurement date" (FASB, 2006). Auditors may use three different input prices to determine FVA, either available prices of identical items in active markets, similar items in an inactive market, or using

mark-to-model approach when observable inputs are not available (Laux \& Leuz, 2009). The complexities of FVA challenges audit profession because estimation and economic uncertainties increase overall task difficulty (Bratten et al., 2013). Since auditing is not an easy task, auditors have to exercise a high competency level of technical capabilities and judgement to produce excellent results.

Prior research argues that the complexity of audit tasks may have a detrimental effect on audit judgement 
because auditors have less optimal usage of proper knowledge when the complexities increase (Bonner, 1994). However, the rise of risk-based audit gives auditors flexibility and adaptability of their plan. As Humphrey \& Moizer (1990) argue that the audit manual already has significant usefulness for auditors to determine approaches and judgement in doing an audit process. Auditors always start from prior years audit working paper, closing meeting agenda and current year fluctuation to plan the audit procedure. If there are any uncertain estimates or changing in economic condition, auditors may exercise their ability to narrow differences, change sample size and determine testing approaches that suitable to address the risks. This situation also recognises that auditor has an underlying sceptical attitude in doing a risk-based audit. Even there have been many debates around the adequacy level of auditor skepticism, audit skepticism is a professional trait build through a long process of learning in being auditor. Quoting from Mennicken \& Power (2013), skepticism is more likely to be a function of personality, learning process and audit firm culture which is hard to measure, but there is no doubt that auditors' professional scepticism is essential for corporate governance. It shows that even the task complexity may challenge auditor judgement and skepticism, it becomes a long-term learning process for auditors to keep alert of any changes in providing their expertise. Auditors' knowledge, capabilities, judgement and professional scepticism construct a strong characteristic of the profession.

\section{Fear and Anxiety in Audit Firm Culture}

As a self-regulated profession, auditor is facing an 'embedded dilemma' between cost and quality in its management control system (McNair, 1991). Audit firm management forced individual auditors to consider and resolve this dilemma through time budgets and efficiency principles. Individual auditors face pressures to deliver high-quality audit but expected to be efficient and minimise chargeable time and realisation rate. However, this trade-off between cost and quality remains undiscussable, which McNair (1991) argued it creates 'permanent distorted communication' and ethical ambivalence implications where audit firms rely on individual auditors and are exposed with risks of audit failure and unprofessional behaviour. During the interview process for his paper, McNair (1991) reported individual auditors sacrifices as follow,

"Public accounting is the most demanding and time-consuming career I have been exposed. Professional accountants put their profession ahead of everything else (family, friends, or any other outside life). I think a lot of people did not plan to devote so much time to it but eventually got pulled into the vicious cycle. I do not agree with this kind of living."

Guénin-Paracini, Malsch, \& Paillé (2014) called auditors assignment as an 'impossible mission'. The aforementioned dilemma between cost and quality critically affect auditor's day-to-day work habit and construct the cultures with fear. Power (2003) demonstrates that auditors' fear and feeling of uncertainty is a bigger issue of audit quality rather than the agency problem itself. There are endless deadlines and pressures for auditor. They need sufficient time and resources to provide good work, but accounting firms require them to provide excellent services with maximum efficiency, meanwhile they have to keep the client pleased to ensure engagement continuity for the next fiscal year. Pentland (1993) validates that auditors primarily endure fears most of the time of audit process and only feel comfort at the end of audit engagement.

Auditors are feeling anxious to be failed in detecting significant anomalies and afraid if their judgement may result in possible mistakes. However, in whatever effort auditors put and signal to outsiders, yet they can't identify themselves as good auditors or not. From various stereotypes attached to the accounting profession, auditor is well-known as a character that almost entirely devoid of feeling (Beard, 1994). In defence of auditing culture, Power (2003) argued that the 'denial of emotions is the auditor's effort at constructing and maintaining rationality to ensure their legitimacy in an environment that rewards rationality'. This elaboration shows that auditors' challenges are unreasonable, in addition to task complexity and uncertainty, auditors live within the embedded fear culture inside the audit firm.

The symbolic traits of having professional expertise in an uncertain and stressful working environment showcase auditing as an impossible task to do. From this point of view, society perceived auditor as the only expert left who is able to do the verification of financial information. The professional task of auditing must be abstract enough that others could not easily replicate it and non-auditors could not readily judge the success or failure of auditors. Auditors earned their legitimacy through their capabilities to face the challenges of task complexity, uncertain accounting estimates, fear and anxiety in working place. The complicated situation with independence issues and conflict of interest ensures that audit expectation gap exists to help auditors maintain their economic success. In this regard, auditors' characteristics, conflicts and cultures contribute to sustaining the gap and benefits auditors to protect the continuation of audit business. 


\section{What Fuels Auditors Criticism?}

At first, audit practitioners and regulators perceived audit expectation gap as a less favourable situation and demanded to close the gap. At this point, this research already explores different perspectives of the gap which actually beneficial for auditors' sustainability and economic success. On the other hand, since society is questioning how auditors perform in making judgement and decisions, the gap may lead to public demand for transparency of the audit process. Thus, public doubt and potential mistrust may fuel auditor's criticism even more.

\section{Demand for Transparency}

Audit exists to help public earn reliable information about companies' financial condition to increase efficiency in capital markets. When public has no trust in audit quality, then audit has no value. As a result of auditors' involvement in fraudulent scandals and the effects of audit expectations gap concept, the public is demanding transparency of audit process. In order to provide greater transparency in audit firm governance, regulators in many jurisdictions began to require audit firms to disclose public transparency reports (Deumes et al., 2012). International Organization of Securities Commissions (IOSCO) consultation report elaborates the benefit of audit firm transparency report to 'increase investor confidence, provide additional necessary information, create competitive environment for audit firms and may enhance audit quality' (IOSCO, 2009). Audit firm transparency report intended to provide insight on audit firm governance and increase audit quality.

Although it seems beneficial for investors, standard setters and regulators to enhance the effectiveness of regulatory mechanisms and improvement of securities markets, demand for transparency are not favourable for auditors itself. This report reveals audit firm strengths and weaknesses, which may be useful for a better corporate governance system, but not for auditor's business consequences. Being distinctive and hard to replicate is helpful for audit firms' stability and economic success. Instead than beneficial, research on transparency report shows that the report does not appear to be directly associated with audit firm quality and it may reveal proprietary information of audit firms (Deumes et al., 2012; La Rosa et al., 2019). To protect the profession, audit policies and procedures needed to be confidential from public, moreover for specific information that requires auditor technical capabilities such as uncertain estimates valuation. Disclosing auditors' private information may produce critiques from readers because auditors' judgements and opinions, which required high technical capabilities to form it, are revealed. Since auditing exists because of the way societies are constituted, rather than become advantageous for auditor, public demand for audit transparency may fuel audit criticism because it reveals confidential information of the audit process.

\section{Mistrust and Communication Difficulty}

The concept of transparency has been taken for granted, turns out enforcing greater transparency in audit process might be not a proper solution in responding to audit criticism. Likewise, the issue of trust and mistrust also grew into a boomerang for the audit profession. Power (1999) expresses that audit society is occupied by a 'distrusting society' where society has to trust audit practice to make the capital market efficiency work. However, it is widely agreed that trust is easier to destroy than to create. Auditors lost their reputation since they get involved in the series of notable accounting scandals. Auditors' failures to meet societal expectations led the public to impaired their trust in auditors. Introducing the debate of transparency in order to increase public trust is not a solution either. Trust is likely to be damaged with greater enforcement of transparency because it will highlight complex processes, difficult trade-offs and under-performance areas (Heald, 2018). With transparency, public distrust is increasing and it may hurt audit business sustainability. Without transparency, audit opacity might be useful for auditors' interest towards their economic success at first, but later when public mistrust rises, audit opacity can be exploited by society. Because audit practitioners aren't able and aren't supposed to make audit more transparent, public doubt and mistrust on audit performance may fuel audit criticism further.

When public trust is deeply eroded, communication between audit practitioners and society may be an answer. However, abundant evidence shows that communication between auditor and users is unsatisfactory, especially through the channel of auditor's standard report (AICPA, 1978). Audit report is a primary mode of communication between auditor and financial statements users. However, the report is not able to clarify any shortcomings and misunderstanding of auditors' role and responsibilities in public's eyes. Evidence shows that users find difficulty to understand audit reports and public still feels unsure about the nature of audit procedures after reading the report (Hermanson et al., 1991; Pound, 1981). The readability issue is an inhibiting factor of communication effectiveness between auditors and society. 
Moreover, for information with high technical expertise and uncertain accounting estimates such as impairment testing, audit reports might be insufficient for auditors to communicate their judgement in a complex and sensitive topic. Financial statement users are unaware of audit limitations and audit practitioners also find it hard to communicate their circumstances to public. The communication difficulty formed mainly because of two things, first, auditors are working with confidential data of financial information which doesn't mean all information could be easily disclosed to public. Secondly, there is communication risk and readability issue since auditors are expert and might be hard for general public to understand the audit language used. In this regard, as the debate of audit expectation gap leads to public mistrust, auditors are limited to defend themselves from public criticism because of communication difficulty.

\section{CONCLUSION}

This research argues that the concept of audit expectation gap is two-fold. The history of auditors' involvement in numerous fraudulent scandals has presented the gap as a recurring problem and destruction for audit professions which requires audit practitioners to make efforts to reduce the gap. However, on the other side, auditors can utilise the gap to be a powerful shield to defend themselves from critics.

The evidence discussed in this research shows three primary contentions. First, auditors manage to take advantage of the change in audit environment and the phenomenon of audit explosion to sustain their economic success, for example by transforming auditors' responsibilities and shifting audit standards towards fraud detection which favourable for audit business sustainability. Despite the criticism addressed to auditors due to various audit failures, the demands for auditors' existence showcased by society makes auditors able to maintain their autonomy to regulate, protect and advance the professions' best interest. Second, the concern of audit independence and conflict of interest associated with auditors extend the gap because the issues may affect auditors' judgement and it hurts public expectations toward auditors. However, instead of auditors' credibility eroded due to the issues, audit professions earned greater public legitimacy. Auditors manage to exhibit their capabilities and professionalism to perform in a complex, uncertain and taxing working environment for a greater public interest which is favourable to maintain the economic success of audit business. Third, the gap develops public demand for audit transparency that damages public trust in auditors. When public mistrust is increasing and audit confidentiality is at stake, auditors aren't capable of clarifying their circumstances because of communication difficulty and issue of readability. This research shows that although the gap can be a defence mechanism for auditors, it might turn to be offensive and fill up criticism.

Above all, the debate of audit expectation gap directs audit researches the needs to reconstruct public trust on auditors. As a third-party actor, auditors' responsibilities to provide certification will be valuable work when trust exists. Since this research acknowledges the limitations of communication difficulty and audit transparency, there are several recommendations provided as a room for development for future research. First, since regulations play an essential role in auditor performance, regulators and standard setters have to strengthen audit-related rules to maintain public trust in regulations. Potential research may evaluate the current rules and consider the needs to change, whether on the content of regulations or regulators point of view. Second, future research may examine the idea of a joint audit, questioning whether the audit should be mutually observed to reinforce public trust. Last but not least, future research should consider an open discussion to rethink audit challenges, including the control of audit, expertise on audit valuation and agenda other than a financial audit. As a continuing research agenda, the discussion of audit expectation gap provided in this research allows readers to reconsider the necessity of reinstalling trust in audit profession.

\section{REFERENCES}

Albrecht, W. S., Albrecht, C. C., Albrecht, C. O., \& Zimbelman, M. F. (2009). Fraud Examination (3rd ed). Mason, $\mathrm{OH}$ : South Western Cengage Learnong.

American Institute of Certified Public Accountants (AICPA). (1939). Extension of Auditing Procedure. Statement on Auditing Procedures No. 1. Retrieved from http://www.aicpa.org/research/standards/auditattest/pages/sas.aspx\#SAS43

American Institute of Certified Public Accountants (AICPA). (1978). The Commission on Auditors' Respon- 
sibilities: Report, Conclusions, and Recommendations (Cohen Commission). In The Commission on Auditors' Responsibilities. Retrieved from http://3197d6d14b5f19f2f440-5e13d29c4c016cf96cbbfd197c579b45.r81.cf1.rackcdn.com/collection/papers/1970/1978_0101_CohenAuditors.pdf

Bazerman, M. H., \& Moore, D. (2011). Is it time for auditor independence yet? Accounting, Organizations and Society, 36(4-5), 310-312. https://doi.org/10.1016/j.aos.2011.07.004

Beard, V. (1994). Popular culture and professional identity: Accountants in the movies. Accounting, Organizations and Society, 19(3), 303-318. https://doi.org/10.1016/0361-3682(94)90038-8

Bonner, S. E. (1994). A Model of The Effects of Audit Task Complexity. Accounting, Organizations and Society, 19(3), 213-234. https://doi.org/10.1007/978-94-011-0745-7_247

Bratten, B., Gaynor, L. M., McDaniel, L., Montague, N. R., \& Sierra, G. E. (2013). The Audit of Fair Values and Other Estimates: The Effects of Underlying Environmental, Task, and Auditor-Specific Factors. Auditing: A Journal of Practice \& Theory, 32(SUPPL.1), 7-44. https://doi.org/10.2308/ajpt-50316

Brown, R. (1962). Changing Audit Objectives and Techniques. The Accounting Review, 37(4), 696-703.

Chui, L., \& Pike, B. (2013). Auditors' Responsibility for Fraud Detection: New Wine in Old Bottles? Journal of Forensic \& Investigative Accounting, 5, 204-233.

Coffee, J. C. (2002). Understanding Enron: "It's about the gatekeepers, stupid." Business Lawyer, 57(4), 14031420. https://doi.org/10.2139/ssrn.325240

Coffee, J. C. (2006). Gatekeepers: The Professions and Corporate Governance. New York: Oxford University Press.

Deumes, R., Schelleman, C., Vander Bauwhede, H., \& Vanstraelen, A. (2012). Audit Firm Governance: Do Transparency Reports Reveal Audit Quality? Auditing: A Journal of Practice \& Theory, 31(4), 193-214. https://doi.org/10.2308/ajpt-10301

Farrell, B., \& Franco, J. (1998). The Changing Role of the Auditor: An Analysis of Viewpoints from the Auditors' Perspective. The Mid - Atlantic Journal of Business, 34(2), 101-124.

Financial Accounting Standards Board (FASB). (2006). Statement of Financial Accounting Standards No. 157 - Fair Value Measurements. Retrieved from https:/www.fasb.org/jsp/FASB/Document_C/DocumentPage?cid $=1218220130001$ \&acceptedDisclaimer $=$ true

Guénin-Paracini, H., Malsch, B., \& Paillé, A. M. (2014). Fear and risk in the audit process. Accounting, Organizations and Society, 39(4), 264-288. https://doi.org/10.1016/j.aos.2014.02.001

Heald, D. (2018). Transparency-generated trust: The problematic theorization of public audit. Financial Accountability and Management, 34(4), 317-335. https://doi.org/10.1111/faam.12175

Hermanson, R. H., Duncan, P. H., \& Carcello, J. V. (1991). Does the new audit report improve communication with investors? Ohio CPA Journal, 50(2), 32-37.

Humphrey, C. (2007). Debating Audit Expectations. In M. Sherer \& S. Turley. Current Issues in Auditing (3rd Edition), 3-30. https://doi.org/http://dx.doi.org/10.4135/9781446219133.n1

Humphrey, C., \& Moizer, P. (1990). From Techniques to Ideologies: An Alternative Perspective on the Audit Function. Critical Perspectives on Accounting, 1, 217-238. https://doi.org/10.1016/1045-2354(90)03021-7

Humphrey, C., Moizer, P., \& Turley, S. (1992). The audit expectations gap-plus ca change, plus c'est la meme chose? Critical Perspectives on Accounting, 3(2), 137-161. https://doi.org/10.1016/1045-2354(92)90008-F

International Organization of Securities Commissions (IOSCO). (2009). Transparency of Firms that Audit Public Companies Consultation Report. In Technical Committee IOSCO Consultation Report. Retrieved from https://www.iosco.org/library/pubdocs/pdf/IOSCOPD302.pdf

Kaplan, R. S., \& Kiron, D. (2007). Accounting Fraud at WorldCom. Harvard Business School Case, 9-104-071.

Kershaw, D. (2006). Waiting for Enron: The unstable equilibrium of auditor independence regulation. Journal of Law and Society, 33(3), 388-420. https://doi.org/10.1111/j.1467-6478.2006.00364.x

La Rosa, F., Caserio, C., \& Bernini, F. (2019). Corporate governance of audit firms: Assessing the usefulness 
of transparency reports in a Europe-wide analysis. Corporate Governance: An International Review, 27(1), 14-32. https://doi.org/10.1111/corg.12235

Laux, C., \& Leuz, C. (2009). The crisis of fair-value accounting: Making sense of the recent debate. Accounting, Organizations and Society, 34(6-7), 826-834. https://doi.org/10.1016/j.aos.2009.04.003

Mancino, J. (1997). The auditor and Fraud. Journal of Accountancy, 183(4), 32-36.

Marczewski, D., \& Akers, M. (2005). CPAs' Perceptions of the Impact of SAS 99. The CPA Journal, 75(6), 38-40.

McNair, C. J. (1991). Proper compromises: The management control dilemma in public accounting and its impact on auditor behavior. Accounting, Organizations and Society, 16(7), 635-653. https://doi. org/10.1016/0361-3682(91)90017-9

Mennicken, A., \& Power, M. (2013). Auditing and Corporate Governance. The Oxford Handbook of Corporate Governance, (November), 308-327. https://doi.org/10.1093/oxfordhb/9780199642007.013.0014

Moizer, P. (2007). Independence. In M. Sherer \& S. Turley. Current Issues in Auditing (3rd Edition), 55-69. https://doi.org/10.4135/9781446219133

Moore, D. A., Tetlock, P. E., Tanlu, L., \& Bazerman, M. H. (2006). Conflicts of interest and the case of auditor independence: Moral seduction and strategic issue cycling. Academy of Management Review, 31(1), 10-29. https://doi.org/10.5465/AMR.2006.19379621

O'Halloran, M. (2008, October 18). Firms "have case to answer" on banks crisis. The Irish Times, p. 1. Retrieved from https://www.irishtimes.com/news/politics/oireachtas/firms-have-case-to-answer-on-banks-crisis- 1.897592

Pentland, B. T. (1993). Getting Comfortable with the Numbers: Auditing and the Micro-production of Macro-order. Accounting, Organizations and Society, 18(7), 605-620.

Porter, B. (1993). An Empirical Study of the Audit Expectation-Performance Gap. Accounting and Business Research, 24(93), 49-68. https://doi.org/10.1080/00014788.1993.9729463

Porter, B. (2007). Auditors' responsibilities with respect to corporate fraud - a controversial issue. In M. Sherer \& S. Turley. Current Issues in Auditing (3rd Edition), 31-54. https://doi.org/http://dx.doi. org/10.4135/9781446219133.n2

Pound, G. D. (1981). Note on Audit Report Readability. Accounting and Finance, 21, 45.

Power, M. (1994). The Audit Explosion. London: Demos.

Power, M. (1999). The Audit Society: Rituals of Verification. https://doi.org/10.1093/acprof:oso/9780198296034.001.0001

Power, M. (2003). Auditing and the production of legitimacy. Accounting, Organizations and Society, 28(4), 379-394. https://doi.org/10.1016/S0361-3682(01)00047-2

Power, M. (2005). The Theory of the Audit Explosion. In Ferlie, Lynn \& Pollitt. The Oxford Handbook of Public Management, Chapter 14, 1-19. https://doi.org/10.1093/oxfordhb/9780199226443.003.0015

Russel, P. (1991). Department of Trade Investigations. In M. Sherer \& S. Turley. Current Issues in Auditing (2nd Edition), 76-98.

Seligman, J. (2002). No One Can Serve Two Masters: Corporate and Securities Law After Enron. Washington University Law Review, 80(2), 449-517.

Sikka, P. (2009). Financial crisis and the silence of the auditors. Accounting, Organizations and Society, 34(6-7), 868-873. https://doi.org/10.1016/j.aos.2009.01.004

Sikka, P., Puxty, A., Willmott, H., \& Cooper, C. (1998). The impossibility of eliminating the expectations gap: Some theory and evidence. Critical Perspectives on Accounting, 9(3), 299-330. https://doi.org/10.1006/ cpac.1997.0159 